Relação entre características funcionais e o desempenho de espécies arbóreas nativas em um plantio de restauração

Relationship between functional traits and performance of native tree species in restoration planting

Bruno Sano

São Paulo, 2016 
Universidade de São Paulo

Instituto de Biociências

Programa de Pós-Graduação em Ecologia

\title{
Relação entre características funcionais e o desempenho de espécies arbóreas nativas em um plantio de restauração
}

Relationship between functional traits and performance of native tree species in restoration planting

\section{Bruno Sano}

\author{
Dissertação apresentada ao Instituto de \\ Biociências da Universidade de São \\ Paulo para obtenção de Título de Mestre \\ em Ciências, na área de Ecologia.
}

Orientadora: Prof ${ }^{\mathrm{a}}$. Dra ${ }^{\mathrm{a}}$. Adriana Maria Zanforlin Martini

São Paulo, 2016 
Ficha Catalográfica

Sano, Bruno

Relação entre características funcionais e o desempenho de espécies arbóreas nativas em um plantio de restauração

Relationship between functional traits and performance of native tree species in restoration planting

pp. 33

Dissertação (Mestrado) - Instituto de Biociências da Universidade de São Paulo.

1. Restauração Ecológica 2. Características funcionais foliares 3. Grupos sucessionais 4. Planície costeira 5. Pastagem 6. Taxa de crescimento relativo I. Universidade de São Paulo. Instituto de Biociências.

Comissão julgadora

Prof (a). Dr (a).

Prof (a). Dr (a).

Prof $^{\text {a }}$. Dra . Adriana Maria Zanforlin Martini 
DEDICATÓRIA

Dedico aos meus pais e avós que sempre me incentivaram a estudar. 


\section{AGRADECIMENTOS}

À Adriana Martini pela orientação, amizade, ensinamentos e estar sempre disposta a me ajudar quando eu mais precisei.

À Petrobras pelo financiamento do projeto "Ecologia e Restauração de Ecossistemas da Planície Costeira no Litoral Norte de São Paulo”, no qual esse projeto está inserido.

À CAPES pela bolsa concedida.

Ao departamento de Ecologia (IB/USP) e Instituto de biociências pelo suporte durante todo o período do meu mestrado. Especialmente à Vera e aos técnicos Gustavo, Lenilda, Geison, Rai e Luis por toda a atenção que deram sempre que precisei.

Aos membros do meu comitê de acompanhamento: Pedro Brancalion, Bruno Rosado e Leda Lorenzo Monteiro pela valiosa contribuição na produção desse trabalho.

Aos companheiros do LABTROP pela amizade, conversas e risadas, em especial à Leticia Zimback (Le) que me ouviu muito e me ajudou mais ainda na fase final do mestrado.

À família Pansonato: Marcelo, Amanda e Ravi pelo acolhimento durante a coleta de dados e principalmente pela amizade.

Às pessoas que me ajudaram em campo: Juliana Vendrami (Ju), Cristiane Millán, Luanne Caires, Renata Ribeiro (me ajudou 2x, muito, muito, muito obrigado!!!), Marcelo Pansonato, Eliane Queiroz e ao Ibere Martins e Leonardo Maraboli que não faziam ideia do que estavam fazendo lá no meio do mato mas me ajudaram muito.

À toda equipe do Curso de campo da Mata Atlântica, pelos ensinamentos, contribuindo para a minha formação profissional e, acima de tudo, pessoal.

Aos meus colegas do curso de campo pela amizade e companheirismo, em especial ao grupo Ergue pelos dias de muita risada.

À Melina Leite e Gustavo Burin pela ajuda com o didático ggplot.

Ao Ricardo Bertoncello pela parceria e por compartilhar alguns dados que foram muito úteis para esse trabalho.

Ao Alexandre Adalardo, Le, Leda, Gabriela Marin, Glauco Machado, Gustavo Requena, Natalia Aristizábal, Adrian Gonzalez e Camila Hohlenwerger pelas conversar que me ajudaram muito durante todo o mestrado. Em especial à $\mathrm{Ju}$, que me ajudou muito em todas as fases dos meus vários projetos, mais ainda na fase final desse trabalho.

Ao Stuart Bird pela ajuda na finalização do trabalho, por me ajudar nesses últimos meses corridos do final do mestrado e principalmente pela amizade de mais de 15 anos. 
Aos companheiros de marmita e bandejão.

Aos meus pais e minha irmã que sempre me apoiaram nessa caminhada.

Aos meus avós que desde sempre me incentivaram a estudar.

A TODOS, MUITO OBRIGADO!!!! 


\section{ÍNDICE}

1. RESUMO

2. ABSTRACT _ 2

3. INTRODUÇÃO — 3

4. MATERIAL E MÉTODOS _ 9

4.1. Área de estudo __ 9

4.2. Delineamento amostral ___ 9

4.3. Sistema de plantio

4.4. Espécies selecionadas___ 11

4.5. Coleta de dados

4.5.1. Crescimento _ 12

4.5.2. Características funcionais __ 12

4.6. Análise de dados ___ 15

5. RESULTADOS _ _ 18

5.1. Crescimento

5.1.1. Altura __ 18

5.1.2. Diâmetro à altura do solo (DAS) _ _ 19

5.2. Características funcionais __ 20

5.3. Relação entre características funcionais e taxa de crescimento relativo _22

6. DISCUSSÃO _ _ 23

7. CONCLUSÕES__ 26

8. REFERÊNCIAS BIBLIOGRÁFICAS _ 27

9. ANEXOS _ 33 


\section{RESUMO}

Em ambientes degradados, a restauração ecológica visa acelerar o processo de sucessão ecológica. A técnica mais utilizada para a restauração de ambientes muito degradados é o plantio de mudas. A seleção das espécies é determinante para o sucesso dos projetos de restauração, pois as espécies precisam se estabelecer e crescer diante das condições do ambiente. Utilizar a abordagem de características funcionais pode ser uma ferramenta promissora para auxiliar a seleção de espécies em projetos de restauração. Em ambientes florestais, há evidências de que as características funcionais afetam o desempenho das espécies, entretanto, existem poucos estudos realizados em áreas em restauração. Neste estudo, foi avaliada a relação entre as características funcionais foliares e a taxa de crescimento relativo em altura e em diâmetro à altura do solo de espécies arbóreas nativas plantadas em uma área degradada que está sendo restaurada. Para descrever a relação entre as características funcionais e a taxa de crescimento relativo (TCR) dos indivíduos foi utilizada a abordagem de seleção de modelos baseados em modelos lineares de efeitos mistos (MLEM). A seleção de modelos foi realizada utilizando o critério de informação de Akaike (Akaike's Information Criterion) (AIC). As características funcionais não apresentaram relação com a taxa de crescimento relativo em altura e diâmetro dos indivíduos das espécies, possivelmente devido às diferenças nas condições ambientais entre ambientes florestais e ambientes degradados. Apesar de não ter sido encontrada uma relação entre as características funcionais e a TCR, o modelo mais plausível selecionado indica que indivíduos maiores no início do monitoramento possuem menores taxas de crescimento relativo em altura, ou seja, indivíduos mais altos possuem menores taxas de crescimento em altura. Isso pode ser um indicativo de que as espécies analisadas possuem taxa de crescimento relativo dependente do tamanho. Considerando que não foi encontrada relação entre as características funcionais morfológicas e a taxa de crescimento relativo em uma área em restauração, é razoável supor que essa abordagem não pode ser utilizada em todos os ambientes. Estudos que avaliem características funcionais foliares nos diferentes estágios de desenvolvimento das plantas em ambientes degradados podem refinar essas análises e ajudar a definir se a seleção de espécies para projetos de restauração pode ser feita usando a abordagem de características funcionais.

Palavras-chave: Restauração ecológica, características funcionais foliares, grupos sucessionais, planície costeira, pastagem, taxa de crescimento relativo 


\section{ABSTRACT}

In degraded environments, ecological restoration aims to accelerate the process of ecological succession. The most widely used technique for restoration of degraded environments is the planting of seedlings. The selection of species is crucial to the success of the restoration projects, because the species need to establish and grow under the harsh conditions of the environment. Using the approach of functional traits can be a promising tool to assist in the selection of species in restoration projects. In forest environments, there is evidence that functional traits affect the performance of the species, however, there are few studies conducted in areas undergoing restoration. In this study, the relationship between the functional leaf traits and the relative growth rate in height and in diameter at ground level of native tree species planted in a degraded area that is being restored was evaluated. To describe the relationship between the functional traits and the relative growth rate (RGR) of individuals, we used the approach of model selection based on linear mixed effects models (LMEM). The selection of models was performed using Akaike's Information Criterion (AIC). The functional traits showed no relationship with the relative growth rate in height and diameter of the individuals of the species, possibly due to differences in environmental conditions between forest environments and degraded environments. Despite not finding a relationship between the functional traits and the RGR, the most plausible model selected indicates that larger individuals at the beginning of monitoring have lower relative growth rates in height, that is, taller individuals have lower rates of growth in height. Considering that no relationship between the morphological functional traits and the relative growth rate in an area undergoing restoration was found, it is reasonable to assume that this approach cannot be applied in all environments. Studies that assess functional traits of the leaf in the different stages of plant development in degraded environments can refine these analyses and help define whether the selection of species for restoration projects can be accomplished using the approach of functional characteristics.

Key words: Restoration ecology, functional leaf traits, successional groups, costal plain, pasture, relative growth rate 


\section{INTRODUÇÃO}

Ecossistemas florestais estão constantemente sujeitos a distúrbios que podem causar pequenos danos ou eliminar quase totalmente a vegetação local. Esses distúrbios podem ser tanto naturais, como a queda de uma árvore, furacões e inundações, quanto causados pelo homem, como queimadas e desflorestamentos para o uso da terra (Chazdon 2008). Após sofrer um distúrbio de grande intensidade, ocorre um processo de recolonização, no qual as espécies que ocuparão inicialmente esses locais precisam possuir características adequadas para sobreviver e se estabelecer diante das condições do ambiente que foi transformado. Com o passar do tempo, as espécies que chegam primeiro podem alterar alguns fatores ambientais, como o microclima local, possibilitando que outras espécies se estabeleçam.

O processo contínuo de colonização e desaparecimento de espécies em um local é denominado sucessão ecológica (Bazzaz 1979). Diversos fatores podem influenciar a dinâmica da sucessão que, em geral, ocorre de forma lenta (Bazzaz \& Pickett 1980, Bradshaw 1983) e pode ter diferentes trajetórias e velocidades dependendo dos fatores que a estão influenciando (Norden et al. 2015). Entre esses fatores, pode-se citar o histórico do uso da terra (Uhl \& Serrão 1988, Chazdon 2008, Mora et al. 2014), a fertilidade do solo, a distância da fonte de propágulos, a presença ou ausência de dispersores e a competição por recursos (Bazzaz \& Pickett 1980). No caso dos fatores acima atuarem de forma intensa ou se as primeiras espécies que colonizam o ambiente perturbado não permitirem que outras espécies germinem e se estabeleçam no local, a sucessão ecológica pode ser mais lenta do que o esperado ou até mesmo ficar estagnada se não houver algum tipo de intervenção humana (Sarmiento 1997, Zahawi \& Augspurger 1999, Goldsmith et al. 2011), como a restauração ecológica.

Em ambientes florestais que foram muito degradados e as condições ambientais estão profundamente alteradas, a restauração ecológica visa acelerar o processo de sucessão 
ecológica. Uma maneira de alcançar esse objetivo é produzir "gatilhos ecológicos", isto é, promover interações interespecíficas diretas ou indiretas que possam impulsionar os processos ecológicos mais rapidamente e que garantam a persistência das comunidades formadas por um longo prazo (Bechara 2006). Em casos que o ambiente está muito degradado e possivelmente não existem regenerantes naturais ou fontes de propágulos próximas, a técnica de restauração mais utilizada é o plantio de sementes e/ou mudas (Ruiz-Jaen \& Aide 2005). O uso dessa técnica elimina algumas barreiras dos estágios iniciais da sucessão, como a baixa dispersão e germinação de sementes e alta predação de sementes (Holl et al. 2000). Entretanto, mesmo com a introdução de mudas de espécies nativas no ambiente, outras barreiras como o consumo por herbívoros e a competição com espécies invasoras dominantes ainda dificultam o estabelecimento e, consequentemente, o sucesso dos projetos de restauração ecológica (Nepstad et al. 1990, Holl et al. 2000).

Uma das dificuldades dos projetos de restauração é a seleção de espécies para o plantio de mudas. As espécies selecionadas precisam ter sucesso no estabelecimento e persistir por um longo prazo nos ambientes degradados. Como as florestas tropicais apresentam alta riqueza de espécies, é praticamente impossível medir as taxas de crescimento e sobrevivência de todas as espécies em diferentes condições para verificar quais possuem melhores desempenhos frente às condições do ambiente degradado. Uma alternativa seria identificar características de fácil acesso (fácil mensuração e que não necessite de equipamentos custosos para serem mensuradas) e que preveem alta sobrevivência e rápido crescimento de acordo com as particularidades de cada ambiente (Pywell et al. 2003, Martínez-Garza et al. 2005). Essas características podem ser identificadas por meio da análise de características funcionais de resposta, que são características morfo-fisio-fenológicas que variam em resposta a mudanças ambientais e que afetam o desempenho (crescimento, sobrevivência e reprodução) dos indivíduos (Violle et al. 2007). Dessa forma, conhecer quais características funcionais 
podem estar mais relacionadas com o desempenho de espécies em ambientes degradados pode ser uma ferramenta promissora para auxiliar as práticas de restauração (Gondard et al. 2003).

Ambientes intensivamente degradados geralmente possuem altos níveis de radiação solar e apresentam solos pouco férteis. Nessas condições, espécies com maiores massas foliares por unidade de área (MFA) provavelmente terão melhores desempenhos. A MFA tem sido frequentemente relacionada com o custo da folha em interceptar a luz, com valores mais altos de MFA sendo encontrados em ambientes com alta radiação solar (Meziane \& Shipley 2001, Poorter et al. 2009). Nesses ambientes as plantas podem produzir folhas menores para a captação da radiação e isso faz com que a massa foliar por área aumente. A MFA também pode ser utilizada como um indicativo de investimento na folha de acordo com a disponibilidade de nutrientes. Plantas em locais com maior disponibilidade de nutrientes possuem folhas com valores menores de MFA (Turner 1994).

Diferentes combinações de características funcionais podem representar diferentes estratégias ecológicas das plantas. Por exemplo, em relação ao uso de recursos, a estratégia aquisitiva é caracterizada por rápidas trocas de folhas e altas taxas de captação de recursos (Reich et al. 2003, Diaz et al. 2004, Wright et al. 2004). As espécies que se enquadram nessa estratégia possuem características funcionais como baixa MFA e alta concentração de nitrogênio nas folhas (Reich et al. 1997, Reich et al. 1999, Wright et al. 2004). Por outro lado, a estratégia conservativa é caracterizada por características funcionais que mantêm os recursos (Poorter \& Garnier 1999), investindo mais nas folhas e evitando a troca de folhas. Espécies com alto MFA, alto conteúdo de matéria seca foliar (CMSF) e baixa concentração de nitrogênio na folha representam essa estratégia. Possivelmente, as diferentes estratégias estão relacionadas ao desempenho das espécies. Espécies com a estratégia aquisitiva em ambientes sem limitação de recursos geralmente constroem folhas para rápida aquisição de recursos e possuem crescimento mais rápido do que espécies com a estratégia conservativa (Poorter \& 
Bongers 2006). Quando as taxas de crescimento relativo das espécies de estratégias diferentes foram comparadas em ambientes com diferentes disponibilidades de recursos, espécies aquisitivas apresentam maiores taxas de crescimento relativo do que espécies com a estratégia conservativa tanto no ambiente com maior ou menor disponibilidade de recursos. Entretanto, as espécies com estratégia aquisitiva são mais sensíveis à diminuição da disponibilidade de recursos e apresentam maiores reduções nas taxas de crescimento relativo quando comparadas com espécies com estratégia conservativa (Poorter 1999).

As espécies podem ser agrupadas de diferentes formas em função das características que possuem. Características como capacidade de germinar, crescer e se estabelecer em diferentes condições de luz são amplamente utilizadas para classificar as espécies em grupos sucessionais (Denslow 1980, Hartshorn 1980, Whitmore 1982, Martinez-Ramos 1985, Vásquez-Yanes \& Sada 1985, Swaine \& Whitmore 1988, Piña-Rodrigues et al. 1990). Em projetos de restauração, geralmente as espécies são selecionadas utilizando a classificação binária de pioneiras e não-pioneiras, que apresentam características morfológicas e fisiológicas distintas (Swaine \& Whitmore 1988). Segundo essa classificação, espécies pioneiras são aquelas que possuem as maiores taxas de crescimento quando comparadas com espécies não-pioneiras e que conseguem germinar apenas em áreas com dossel aberto, onde a luz chega diretamente ao solo por, pelo menos, parte do dia. As não-pioneiras são espécies que conseguem germinar na sombra, muito raramente na presença de luz total. Embora a classificação separe as espécies em dois grupos distintos os autores reconhecem que há um gradiente de tolerância à luz entre os dois grupos. Mesmo com a classificação de espécies em grupos bastante contrastantes em determinadas características, outras características podem apresentar variação dentro dos grupos e essa variação pode ajudar a explicar diferentes desempenhos das espécies dentro de um mesmo grupo. 
O desempenho das plantas pode ser influenciado também por fatores genéticos intrínsecos das plantas e pelo estágio de desenvolvimento (Hérault et al. 2011). Por exemplo, a taxa de crescimento das plantas pode ser maior com o aumento do tamanho em espécies de plantas que buscam melhor acesso à luz. Entretanto, quando as plantas alcançam o dossel, investir recursos em altura talvez não seja mais tão vantajoso e investir os recursos em expansão da copa para maximizar a captação de luz (Poorter, Bongers \& Bongers 2006) ou em diâmetro para melhorar a sustentação pode trazer mais benefícios para as plantas. Além disso, as plantas podem simplesmente realocar recursos para outras finalidades como a reprodução (Thomas 1996). Portanto, as taxas de crescimento das plantas devem aumentar gradativamente a partir dos primeiros estágios de desenvolvimento e conforme alcançam estágios mais avançados tendem a desacelerar (Paine et al. 2012), de modo que as maiores taxas de crescimento devem ocorrer em tamanhos intermediários (Hérault et al. 2011). Dessa forma, é razoável pensar que a relação entre características funcionais e a taxa de crescimento de crescimento relativo seja influenciada pelo tamanho ou pelo estágio de desenvolvimento das plantas.

Considerando que em ambientes degradados há altos níveis de radiação solar e solos empobrecidos e que as espécies utilizadas para restauração podem apresentar diferentes desempenhos frente a essas condições ambientais, se as características funcionais foliares estiverem associadas a um uso mais eficiente de recursos ou maior tolerância a condições estressantes, seria possível identificar as características das espécies com melhores desempenhos. Diante disso, o objetivo desse trabalho foi verificar se características foliares estão relacionadas ao crescimento de indivíduos de espécies arbóreas nativas plantadas em uma área degradada que está sendo restaurada. Existem evidências de que as características funcionais estão relacionadas com as taxas de crescimento relativo em ambientes florestais (Poorter 1999, Martínez-Garza et al. 2005, Sterk et al. 2006, Poorter et at. 2008, Wright et al. 
2010), mas poucos estudos testaram essa relação em áreas degradadas. Se essas relações forem encontradas, pesquisas experimentais que analisam quais espécies apresentam melhor desempenho frente às condições ambientais de ambientes degradados poderiam ser substituídas pela mensuração das características funcionais, que são relativamente mais fáceis de ser obtidas. Isso facilitaria a seleção de espécies e aumentaria as chances de sucesso dos projetos. 


\section{MATERIAL E MÉTODOS}

\section{1. Área de estudo}

A área de estudo está localizada no município de Caraguatatuba, no litoral norte do Estado de São Paulo (latitude $23^{\circ} 65^{\prime} 37^{\prime}$ 'S, longitude $45^{\circ} 50^{\prime} 16^{\prime \prime} \mathrm{W}$ ), ao lado da Unidade de Tratamento de Gás Monteiro Lobato - UTGCA (Figura 1). Essa área é uma APP (Área de Preservação Permanente) do Rio Camburu cujas matas ciliares encontram-se degradadas. O solo original da região é do tipo neossolo, porém devido a um deslizamento de terra em 1967, a região possui uma camada de materiais superficiais, que desceram da escarpa da serra do mar, com características mais argilosas (Colangelo 2012, Ferreira 2013) do que existia na planície costeira. O clima é Af (tropical úmido) segundo a classificação Köppen (1948), influenciado predominantemente pelas massas equatoriais e tropicais. A temperatura média anual é de $24,9^{\circ} \mathrm{C}$ e a precipitação média anual é de $1757,9 \mathrm{~mm}$ (http://www.cpa.unicamp.br/outras-informacoes/clima_muni_121.html acesso em: 01/02/2016). Essa área foi utilizada como pastagem para criação de gado por muitos anos, sendo a vegetação caracterizada, até então, por gramíneas exóticas invasoras, como Brachiaria sp. e Melinis minutiflora utilizadas na alimentação do gado.

\subsection{Delineamento amostral}

O presente estudo está inserido em um projeto mais amplo chamado "Ecologia e Restauração de Ecossistemas da Planície Costeira no Litoral Norte de São Paulo”, uma parceria entre a Petrobras e o Laboratório de Florestas Tropicais (LabTrop) do Instituto de Biociências da Universidade de São Paulo. Esse projeto de restauração visa analisar diferentes técnicas de plantio, entre elas o plantio convencional em linhas. Após a remoção da parte área das gramíneas exóticas invasoras, foram plantadas 15.693 mudas de 54 espécies arbóreas nativas da Floresta de Restinga, produzidas a partir de matrizes localizadas em ecossistemas da planície costeira do litoral de São Paulo. 
O projeto de restauração foi implementado em fevereiro de 2012. Parte dessa área (aproximadamente 5,5 ha) (figura 1) foi dividida em oito blocos contíguos e cada bloco foi subdividido em sete parcelas de aproximadamente 20 x $50 \mathrm{~m}$. Seis parcelas são referentes às combinações de tratamentos (técnica de plantio x tratamento de nutrientes) e uma parcela corresponde ao controle que não sofreu nenhum tratamento.

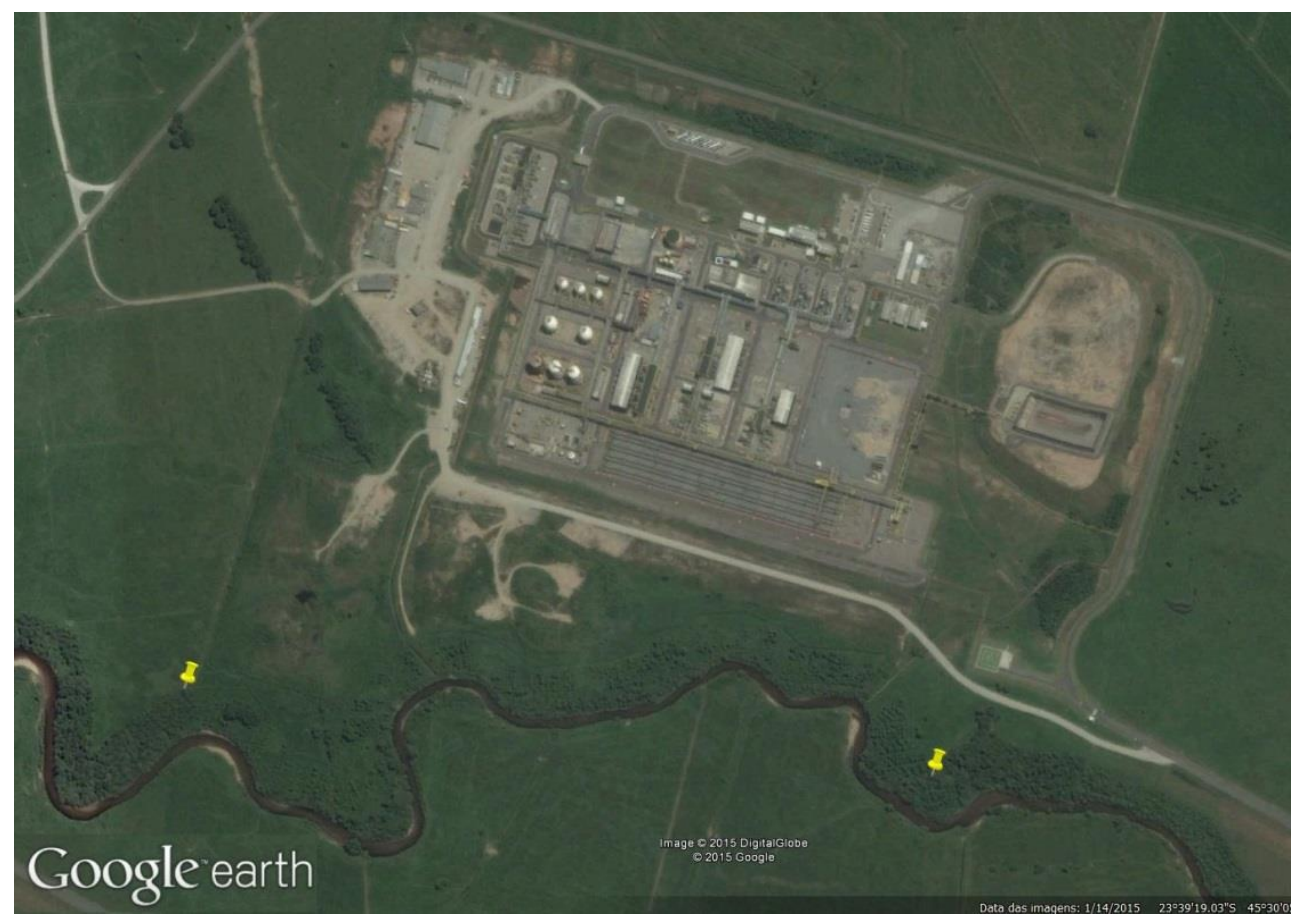

Figura 1: Imagem da área onde está ocorrendo o projeto de restauração no município de Caraguatatuba no estado de São Paulo. Os marcadores amarelos indicam os limites da área que está sendo restaurada. Retirado em: 23/09/2015, Google Earth.

\subsection{Sistema de plantio}

No presente estudo, foram utilizadas as parcelas de tratamento do plantio em linha (LI) e sem adição de nutrientes (ND), que totalizam oito parcelas (uma em cada bloco). Cada uma dessas parcelas (LI_ND) possui 10 linhas de plantio equidistantes entre si de $2 \mathrm{~m}$, sendo que cinco linhas são compostas por espécies pioneiras (P) intercaladas com cinco linhas de espécies não-pioneiras (NP). Cada linha contém aproximadamente 25 plantas com espaçamento entre as plantas de $2 \mathrm{~m}$. Assim, cada parcela de linha possui aproximadamente 
250 indivíduos de, no mínimo, 20 espécies arbóreas. A classificação das espécies entre pioneira e não-pioneira foi obtida a partir da lista de espécies para recuperação de áreas degradadas, disponível no Instituto de Botânica de São Paulo (IBt, http://botanica.sp.gov.br/cerad/cerad-ferramentas-para-restauracao/). A única exceção em relação a essa lista atual é a espécie Solanum cinnamomeum, que na época em que o projeto se iniciou (2011/2012) era classificada como pioneira e atualmente é classificada como nãopioneira.

\subsection{Espécies selecionadas}

Entre o total de espécies utilizadas, foram selecionadas somente as espécies presentes no plantio em linha sem adição de nutrientes que vêm sendo monitoradas desde o início do projeto e que tinham no mínimo 5 indivíduos por parcela (Tabela 1).

Tabela 1. Lista de espécies selecionadas para o presente estudo, com suas respectivas famílias, grupo ecológico a que pertencem.

\begin{tabular}{llll}
\hline Espécie & Família & Sigla & Grupo ecológico \\
\hline Myrsine coriacea (SW.) R.Br. & Primulaceae & Myr cor & Pioneira \\
Schinus terebinthifolius Raddi & Anacardiaceae & Sch ter & Pioneira \\
Erythrina speciosa Andrews & Leguminosae & Ery spe & Pioneira \\
Citharexylum myrianthum Cham. & Verbenaceae & Cit myr & Pioneira \\
Aegiphila verticillata Vell. & Lamiaceae & Aeg ver & Pioneira \\
Solanum cinnamomeum Sendtn & Solanaceae & Sol cin & Pioneira \\
Calophyllum brasiliense Cambess. & Clusiaceae & Cal bra & Não-Pioneira \\
Jacaranda puberula Cham. & Bignoniaceae & Jac pub & Não-Pioneira \\
Ocotea pulchella (Nees \& Mart.) Mez & Lauraceae & Oco pul & Não-Pioneira \\
Eugenia astringens Cambess. & Myrtaceae & Eug ast & Não-Pioneira \\
Eugenia brasiliensis Lam. & Myrtaceae & Eug bra & Não-Pioneira \\
Eriotheca pentaphylla (Vell.) A. Robyns & Malvaceae & Eri pen & Não-Pioneira \\
\hline
\end{tabular}




\subsection{Coleta de dados}

\subsubsection{Crescimento}

Nas parcelas LI_ND, foram realizados cinco monitoramentos desde 2012 (Tabela 2). O monitoramento consistia em avaliar se o indivíduo estava vivo ou morto e medir altura (distância do solo até a gema apical) e diâmetro à altura do solo (DAS). O DAS era medido com paquímetro até valores próximos a $60 \mathrm{~mm}$, e a partir desse valor, era medido com fita métrica. Além disso, eram feitas duas medidas de DAS por indivíduo, sendo cada medida em planos perpendiculares, de modo a ponderar pela irregularidade do tronco. Assim, o DAS final de cada indivíduo em cada monitoramento, representa a média dessas duas medidas. A altura dos indivíduos era medida com uma régua. Além disso, era feito periodicamente o controle das gramíneas invasoras. No período entre T1 e T4, o controle das gramíneas invasoras foi realizado a cada 3 meses, com auxílio de roçadeiras (capina mecânica da parte aérea). Após o T4, o plantio ficou 18 meses sem controle das gramíneas invasoras. No início do mês de setembro de 2015 houve um novo monitoramento (T5), após a remoção das gramíneas invasoras.

Tabela 2. Datas dos monitoramentos realizados no presente estudo e intervalos entre os monitoramentos.

\begin{tabular}{ccc}
\hline Monitoramento & $\begin{array}{c}\text { Data do } \\
\text { monitoramento }\end{array}$ & $\begin{array}{c}\text { Intervalo entre os } \\
\text { monitoramentos (meses) }\end{array}$ \\
\hline T1 & Agosto de 2012 & - \\
T2 & Fevereiro de 2013 & 6 \\
T3 & Agosto de 2013 & 6 \\
T4 & Março de 2014 & 7 \\
T5 & Setembro de 2015 & 18 \\
\hline
\end{tabular}

\subsubsection{Características Funcionais}

Em cada parcela, foram sorteados 3 indivíduos para a coleta das características funcionais. Para cada indivíduo sorteado, foram sorteadas 5 folhas que estivessem totalmente 
expandidas, expostas à radiação solar, voltadas para a direção Norte e, sempre que possível, estivessem sem consumo por herbívoros e saudáveis. Para indivíduos com folhas compostas (Erythrina speciosa, Eriotheca pentaphylla, Jacaranda puberula e Schinus terebinthifolius) foram coletadas apenas 3 folhas. Após a coleta, os ramos com as folhas ficaram em um recipiente com água por, no mínimo, 2 horas para reidratarem. Todas as medidas foram mensuradas no mesmo dia da coleta das folhas, exceto o peso seco da folha pois as folhas tinham que ir para estufa para desidratar. Os pecíolos e raques não foram incluídos nas análises. Para cada folha foram mensuradas, seguindo o protocolo de Pérez-Harguindeguy et at. (2013), as seguintes características funcionais:

- AF - Área Foliar $\left(\mathrm{mm}^{2}\right)$ : As folhas de cada indivíduo foram digitalizadas com um scanner e foi usado o programa ImageJ (Rasband 2007) para calcular aárea das imagens. Em função de alguns indivíduos possuírem todas as folhas com evidências de consumo por herbívoros, a área perdida por consumo de herbívoros foi incluída no cálculo de AF. A AF está relacionada com captação de luz e capacidade fotossintética. Altos valores de AF indicam maior capacidade fotossintética e baixos valores de AF indicam baixa capacidade fotossintética (Pérez-Harguindeguy et at. (2013).

- CMSF - Conteúdo de Matéria Seca da Folha (mg.g $\left.{ }^{-1}\right)$ : Para o cálculo de CMSF a massa seca é dividida pela massa fresca da folha. A massa fresca da folha foi obtida com auxílio de uma balança digital com precisão de 0,001g. Para obter a massa seca da folha as folhas foram colocadas em uma estufa a $60^{\circ} \mathrm{C}$ por, no mínimo, 72 horas. Depois de secas as folhas foram novamente mensuradas com o auxílio da balança digital com precisão de $0,001 \mathrm{~g}$. Quando as folhas tinham massas inferiores à precisão da balança digital de precisão $0,001 \mathrm{~g}$, as folhas eram mensuradas com uma balança digital de precisão 0,0001g. O CMSF pode dar um indicativo da fertilidade do solo. Valores baixos de CMSF estão relacionados com ambientes ricos em nutrientes. O CMSF também está relacionado positivamente com 
longevidade da folha e proteção contra danos físicos e negativamente com a taxa de crescimento relativo (Hodgson et al. 2011). Além disso, pode dar um indicativo da fertilidade do solo. Folhas com valores baixos de CMSF estão relacionados com ambientes ricos em nutrientes (Pérez-Harguindeguy et at. (2013).

- MFA - Massa Foliar por Área (g.m²): Para o cálculo da MFA, a massa seca da folha foi dividida pela área da folha. A massa seca foliar foi medida com o auxílio de uma balança digital com precisão de 0,001g. A MFA está relacionada com o crescimento relativo da planta. Folhas com valores altos de MFA indicam grande investimento na estrutura foliar, aumentando assim a vida útil das mesmas (Pérez-Harguindeguy et at. (2013) e tendem a ser negativamente correlacionadas com as taxas de crescimento relativo (Pérez-Harguindeguy et at. (2013).

- ESP - Espessura (mm): Para o cálculo da espessura foi utilizado um paquímetro digital com precisão de $0,01 \mathrm{~mm}$. Para cada folha foram tomadas 3 medidas na região central do limbo, evitando as nervuras principais. O valor para cada indivíduo foi obtido a partir da média das 3 medidas. A espessura da folha está relacionada positivamente com a capacidade fotossintética. $\mathrm{O}$ aumento da espessura é acompanhado do aumento da quantidade camadas do mesofilo da folha e essas camadas possuem proteínas utilizadas na fotossíntese. Por consequência, pode aumentar as taxas de crescimento da planta (Niinemets 1999).

- DEN - Densidade da folha $\left(\mathrm{g} \cdot \mathrm{m}^{-2} \cdot \mathrm{mm}^{-1}\right)$ : A densidade foi obtida através da fórmula:

$$
D E N=M F A / E S P
$$

A densidade está relacionada com a capacidade fotossintética da folha. Folhas mais densas dificultam a difusão do $\mathrm{CO}_{2}$ para os sítios de carboxilação, dificultando a fotossíntese. (Niinemets 1999). Portanto, altos valores de DEN indicam baixa capacidade fotossintética. 
- Deciduidade: Foram utilizados dados de observações feitas na própria área de estudo durante os 3 anos de monitoramento. As espécies que perdiam totalmente suas folhas em alguma época do ano foram registradas.

\subsection{Análises de dados}

Para calcular a taxa de crescimento relativo em altura e em diâmetro à altura do solo (DAS) entre o tempo T1 e T5, foi utilizada a equação (1) indicada por Hoffmann \& Poorter (2002).

$$
\mathrm{TCR}=[\ln (\mathrm{D} 5)-\ln (\mathrm{D} 1)] / \Delta \mathrm{T} 5-\mathrm{T} 1
$$

Em que TCR é a taxa de crescimento relativo, D5 é a variável resposta no tempo T5, D1 é a variável resposta no tempo T1 e $\Delta \mathrm{T} 5$-T1 é a variação de tempo entre T5 e T1.

Para descrever a relação entre as características funcionais e a taxa de crescimento relativo (TCR) dos indivíduos foi utilizada a abordagem de seleção de modelos baseados em modelos lineares de efeitos mistos (MLEM). Modelos lineares de efeitos mistos descrevem a relação entre a variável resposta e outras covariáveis e são indicados para análises em que os dados são agrupados (p.ex. dados hierárquicos e dados com medidas repetidas) (Pinheiro \& Bates 2000). Esses modelos permitem a inclusão de efeitos aleatórios que possibilitam a análise dos efeitos inerentes a unidades experimentais e/ou amostrais. Por consequência, é possível descontar os efeitos das variáveis aleatórias dos efeitos das variáveis de interesse que estão vinculadas às unidades experimentais e/ou amostrais (Pinheiro \& Bates 2000).

Os modelos foram construídos utilizando as taxas de crescimento relativo em altura e em diâmetro dos indivíduos como variáveis respostas. As espécies e blocos entraram em todos os modelos como variáveis aleatórias. As características funcionais médias de cada espécie, MFA, AF, CMSF e ESP entraram nos modelos como variáveis fixas. A variável 
DEN foi excluída das análises devido à alta correlação com as variáveis MFA e CMSF (Anexo1). Além das características funcionais, a altura no tempo T1 e a classificação sucessional entrar nos modelos como variáveis fixas. O modelo nulo é o modelo que possui apenas as variáveis aleatórias. A partir desse modelo são criados modelos em que são adicionados sequencialmente as variáveis fixas, e as interações que fazem sentido biológico. Foram testadas interações entre as características funcionais e a classificação de grupo sucessional (pioneira e não-pioneira), pois é esperado que espécies de crescimento rápido (pioneira) possuam características morfológicas diferentes das espécies de crescimento lento (não-pioneira). Em ambientes com alta radiação solar, espécies pioneiras devem produzir folhas com características que permitam realizar altas taxas fotossintéticas para investir em crescimento em altura. Por outro lado, as espécies não-pioneiras devem produzir folhas que tolerem a alta radiação solar e invistam em sobrevivência. Outra interação analisada foi entre as características funcionais e a deciduidade (decídua e perene). A deciduidade pode estar relacionada com o investimento que a planta faz nas folhas. Espécies que perdem totalmente suas folhas durante uma época do ano podem investir menos nutrientes nas folhas do que as espécies que mantém suas folhas durante o ano todo (Cornelissen et al. 1996, Poorter et al. 2008). Os dados das características funcionais AF, MFA, ESP, CMSF e altura no tempo T1 possuem unidades muito diferentes e tiveram que ser escalonados. Para escalonar os dados, cada variável foi subtraída pela média e dividida pelo desvio padrão.

A seleção de modelos foi realizada utilizando o critério de informação de Akaike (Akaike's Information Criterion) (AIC). O modelo com menor AIC é considerado o modelo mais plausível (Burnham \& Anderson 2002). Modelos com $\Delta$ AIC <2 são considerados igualmente plausíveis (Johnson \& Omland 2004). Quando dois ou mais modelos possuem $\Delta$ AIC $<2$ o modelo mais parcimonioso foi considerado o modelo mais plausível. Todas as 
análises foram realizadas no ambiente R versão 3.2.3 (R Development Core Team 2015) com o pacote lme4 (Bates et al. 2014) e MuMIn (Bartoń 2015). 


\section{RESULTADOS}

\subsection{Crescimento}

\subsubsection{Altura}

No total foram analisados 308 indivíduos de 12 espécies que estavam vivos no monitoramento T5. Ao final do monitoramento de 3 anos, a altura média das espécies variou entre 88,3 (Ocotea pulchella) e 637,0cm (Citharexylum myrianthum). A média da taxa de crescimento relativo (TCR) em altura das espécies do grupo pioneiras variou entre 0,046 (Erythrina speciosa) e 0,075 cm.mês ${ }^{-1}$ (Myrsine coriacea). No grupo das espécies nãopioneiras, a média da TCR variou entre 0,037 (Eugenia brasiliensis) e 0,071 cm.mês ${ }^{-1}$ (Jacaranda puberula) (Figura 3).

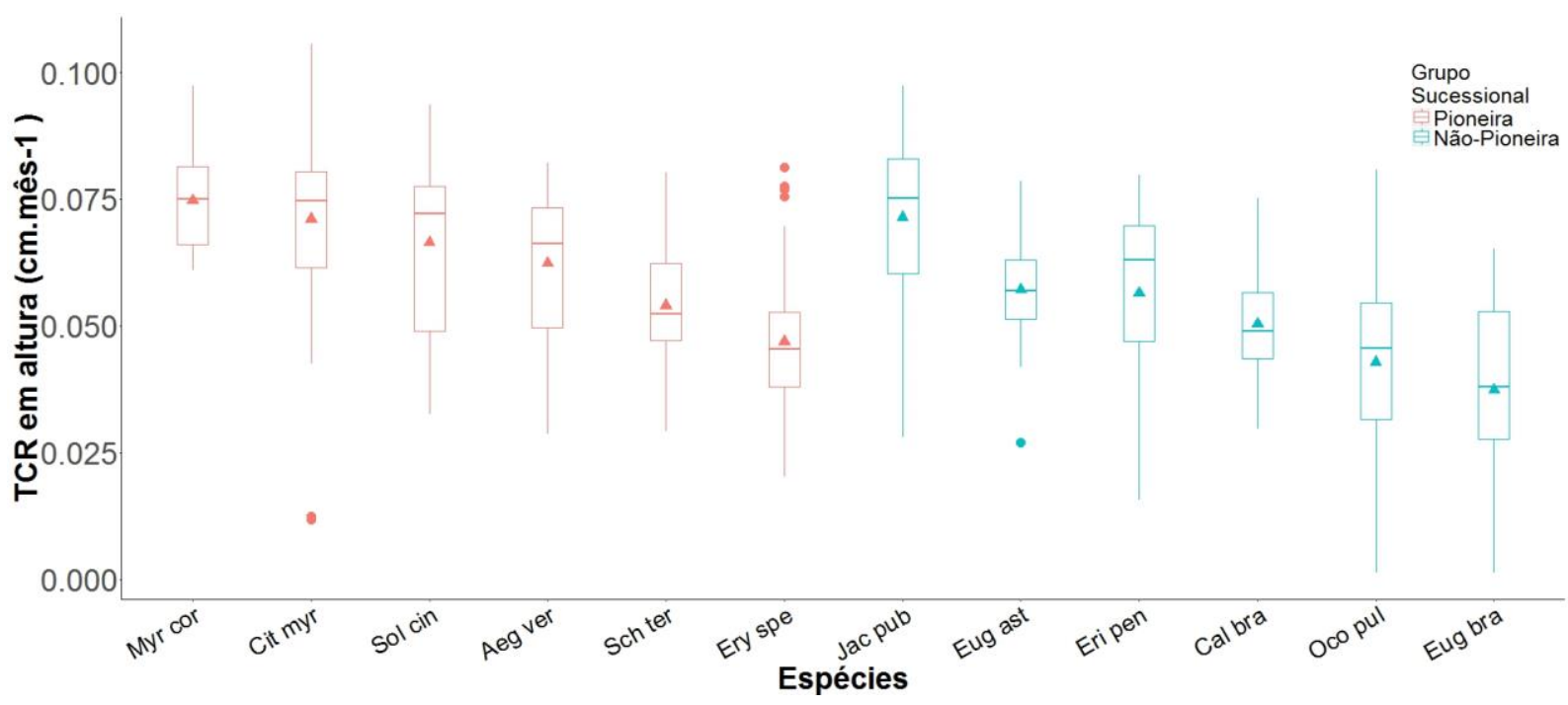

Figura 3: Distribuição dos valores das taxas de crescimento relativo (TCR) em altura dos indivíduos de espécies arbóreas nativas em um plantio de restauração após 3 anos de monitoramento. As linhas mais espessas representam as medianas. As caixas são delimitadas pelo segundo e terceiro quartil, as extremidades das linhas verticais representam o intervalo de confiança de 95\%, os círculos representam os pontos extremos e os triângulos representam as médias. Abreviaturas dos nomes das espécies de acordo com a Tabela 1. 


\subsubsection{Diâmetro à altura do solo (DAS)}

Após 3 anos de monitoramento, o diâmetro à altura do solo (DAS) médio das espécies variou entre 19,6 (Ocotea pulchella) e 180,7mm (Citharexylum myrianthum). No grupo das espécies pioneiras, a média da TCR em DAS das espécies variou entre 0,033 (Erythrina speciosa) e 0,076 mm.mês ${ }^{-1}$ (Solanum cinnamomeum ). A média da TCR em DAS das espécies do grupo não-pioneiras variou entre 0,036 (Eugenia brasiliensis) e 0,058 mm.mês ${ }^{-1}$ (Calophyllum brasiliense) (Figura 4). No grupo das espécies pioneiras, Schinus terebinthifolius apresentou uma taxa de crescimento relativo em DAS acima da média mas por outro lado, apresentou a segunda pior taxa de crescimento relativo em altura. Entre as espécies não-pioneiras, Calophyllum brasiliense apresentou o maior crescimento em DAS, mas crescimento em altura relativamente lento.

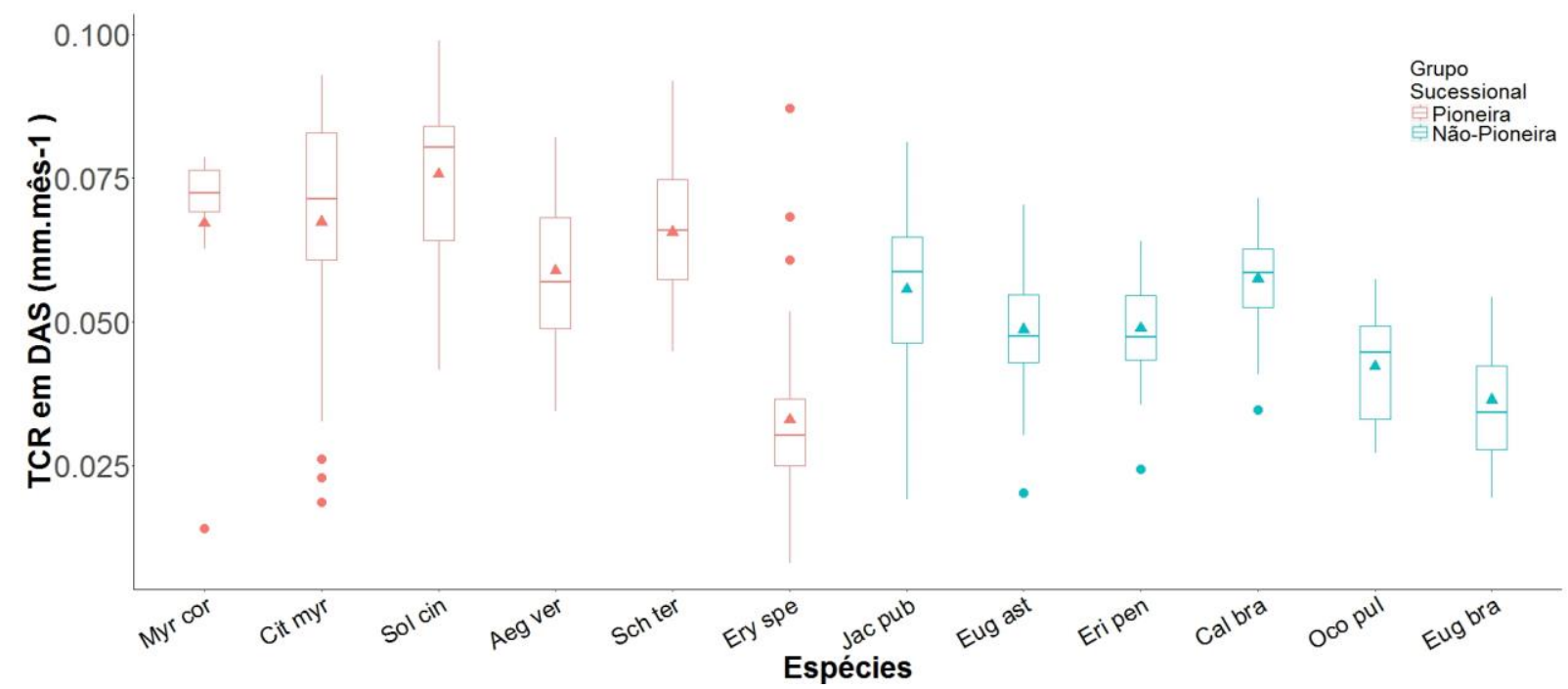

Figura 4: Distribuição dos valores das taxas de crescimento relativo (TCR) em diâmetro à altura do solo dos indivíduos de espécies arbóreas nativas em um plantio de restauração após 3 anos de monitoramento. As linhas mais espessas representam as medianas. As caixas são delimitadas pelo segundo e terceiro quartil, as extremidades das linhas verticais representam o intervalo de confiança de 95\%, os círculos representam os pontos extremos e os triângulos representam as médias. Abreviaturas dos nomes das espécies de acordo com a Tabela 1. 


\subsection{Características funcionais}

Entre os 308 indivíduos analisados, 266 indivíduos tiveram as características funcionais mensuradas. As características funcionais dos indivíduos das espécies tiveram variação relativamente baixa, com exceção da área foliar (AF). O conteúdo de matéria seca foliar (CMSF) variou duas vezes $\left(220,2\right.$ e 442,2 $\left.\mathrm{mg} \cdot \mathrm{g}^{-1}\right)$, a espessura da folha (ESP) três vezes $(0,17$ - 0,48 mm), a massa foliar por área (MFA) três vezes $\left(42,67-130,77\right.$ g.m $\left.{ }^{-2}\right)$. A AF teve a maior variação, na ordem de 43.697 vezes $\left(201,55\right.$ - $\left.8.807 .273 \mathrm{~mm}^{2}\right)$. A espécie Erythrina speciosa apresentou os menores valores para CMSF e MFA e o maior valor para AF e a espécie Ocotea pulchella apresentou o menor valor para AF e o maior valor para CMSF (Figura 5). 


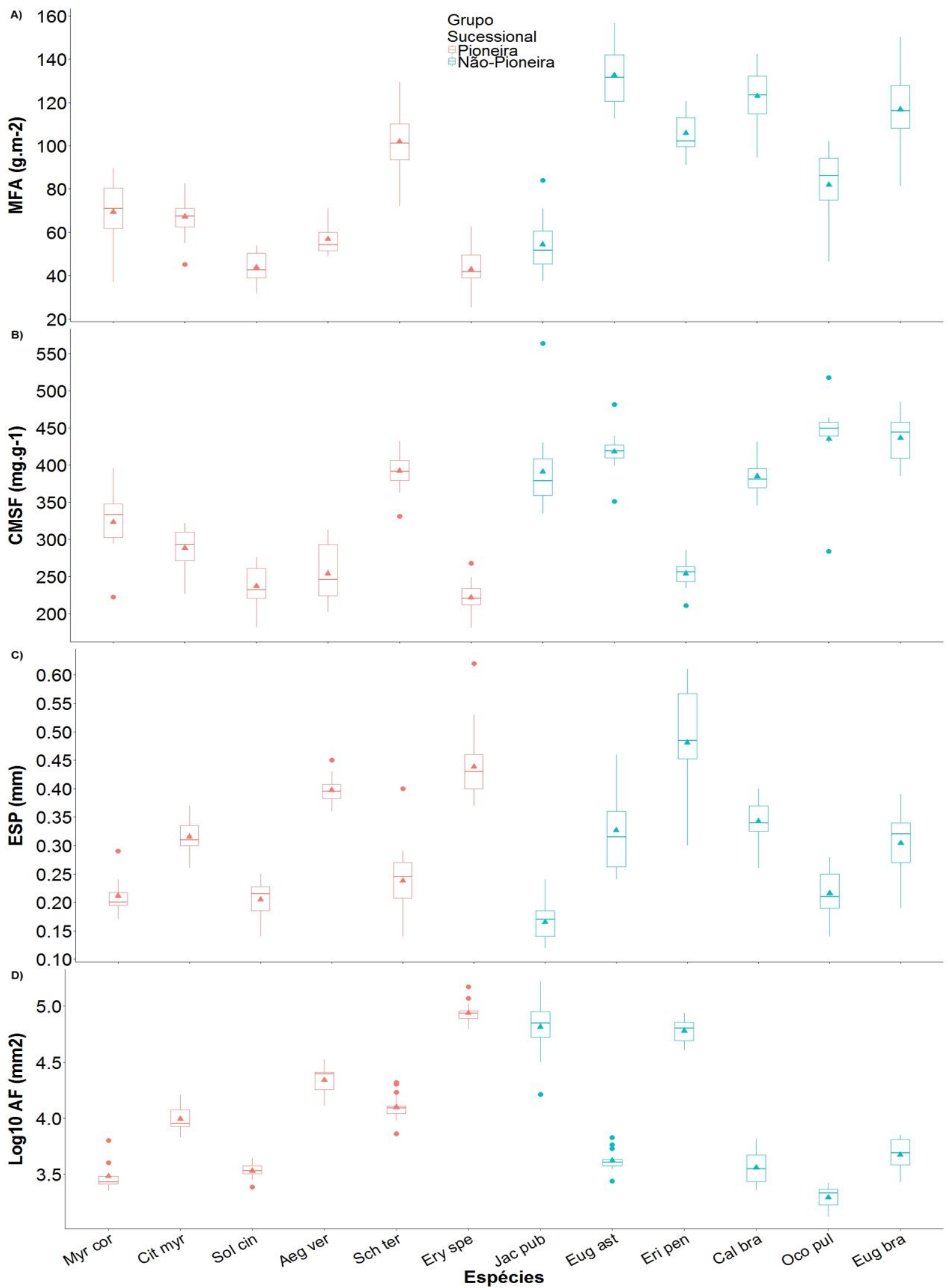

Figura 5: Distribuição dos valores das características funcionais dos indivíduos de espécies arbóreas nativas em um plantio de restauração após 3 anos de monitoramento. As linhas mais espessas representam as medianas. As caixas são delimitadas pelo segundo e terceiro quartil, as extremidades das linhas verticais representam o intervalo de confiança de $95 \%$, os círculos representam os pontos extremos e os triângulos representam as médias. Abreviaturas dos nomes das espécies de acordo com a Tabela 1. A) MFA - Massa foliar por área, B) CMSF - Conteúdo de matéria seca foliar, C) ESP - Espessura foliar, D) AF - Logaritmo na base da Área foliar (para facilitar a visualização, os valores estão em $\log$ ). 


\subsection{Relação entre características funcionais e a taxa de crescimento relativo}

As características funcionais analisadas não influenciaram as taxas de crescimento relativo (TCR) tanto em altura quanto em DAS (Tabela 3). A classificação de grupo sucessional e a deciduidade também não teve relação com a TCR das espécies analisadas. As interações analisadas (grupo sucessional $\mathrm{x}$ características funcionais $\mathrm{e}$ deciduidade $\mathrm{x}$ características funcionais) também não influenciaram as TCR das espécies. Entretanto, para crescimento em altura, o modelo selecionado indica que a altura no tempo T1 é inversamente relacionada com a TCR, ou seja, indivíduos mais altos possuem menores taxas de crescimento em altura.

Tabela 3: Valores dos coeficientes das variáveis dos três modelos com os melhores ajustes entre os modelos que analisavam as interações entre características funcionais e deciduidade

TCR em Altura

TCR em DAS

\begin{tabular}{|c|c|c|c|c|c|c|c|}
\hline $\mathrm{AICc}$ & $-3228,5$ & $-3215,9$ & $-3213,7$ & & $-3265,8$ & $-3252,2$ & $-3251,9$ \\
\hline deltaAICc & 0 & 12,6 & 14,8 & & 0 & 13,6 & 13,9 \\
\hline Weight & 0,996 & 0.002 & 0.001 & & 0,997 & 0,001 & 0,001 \\
\hline \multicolumn{8}{|l|}{ Variáveis } \\
\hline MFA & --- & --- & --- & --- & --- & --- & --- \\
\hline CMSF & --- & --- & --- & -- & --- & --- & --- \\
\hline $\mathrm{AF}$ & --- & --- & --- & -- & --- & --- & --- \\
\hline ESP & --- & --- & --- & -- & --- & --- & --- \\
\hline H1 & $-0,00024$ & $-0,00024$ & $-0,00024$ & & & $-0,00009$ & \\
\hline DEC & --- & --- & 0,00035 & -- & --- & --- & $-0,0004$ \\
\hline GS & --- & $-0,00047$ & --- & -- & --- & --- & --- \\
\hline $\begin{array}{c}\text { MFA x } \\
\text { DEC }\end{array}$ & --- & --- & --- & -- & --- & --- & --- \\
\hline $\begin{array}{c}\text { CMSF x } \\
\text { DEC }\end{array}$ & --- & --- & --- & --- & --- & --- & --- \\
\hline AF x DEC & --- & --- & --- & --- & --- & --- & --- \\
\hline $\begin{array}{c}\text { ESP x } \\
\text { DEC }\end{array}$ & --- & --- & --- & --- & --- & --- & --- \\
\hline H1 x GS & --- & --- & --- & --- & --- & --- & --- \\
\hline
\end{tabular}




\section{DISCUSSÃO}

Neste estudo foi investigada a relação entre as características funcionais e o crescimento de espécies arbóreas nativas após 3 anos de monitoramento em um plantio de restauração. Embora alguns estudos demostrem que características funcionais influenciam o crescimento das plantas em florestas tropicais (Poorter 1999, Martínez-Garza et al. 2005, Sterk et al. 2006, Poorter 2008, Wright et al. 2010), o resultado deste estudo indica que em um ambiente que foi utilizado para pastagem e que agora está em uma fase inicial de um projeto de restauração as características funcionais foliares não influenciaram o crescimento das espécies estudadas.

O fato de não ter encontrado relação entre as características funcionais e o crescimento das espécies pode ter algumas explicações relacionadas às condições do ambiente e ao estágio de desenvolvimento das plantas. Relações entre características funcionais foliares e a taxa de crescimento relativo foram encontradas em ambientes florestais em estágio sucessional intermediário a avançado (Poorter 1999, Ruger et al. 2012, Martínez-Garza et al. 2005). Entretanto, as diferenças abióticas entre ambientes florestais e áreas em processo de restauração, no que diz respeito às condições do solo e quantidade de radiação solar que está disponível para as plantas, pode fazer com que as características funcionais não influenciem a taxa de crescimento relativo. As plantas produzem folhas com características diferentes em ambientes abertos e fechados diante das diferentes condições abióticas desses ambientes e essas diferenças ajudam a explicar os diferentes desempenhos das plantas (Lusk et al. 2011, Lusk \& Jorgensen 2013, Reich 2014). Folhas que estão expostas à alta radiação solar, quando comparadas com folhas que estão na sombra, são mais espessas, provavelmente para evitar superaquecimento (Bongers \& Popma 1998). Além disso, essas folhas possuem maiores concentrações de nutrientes por unidade de área foliar, sugerindo maior capacidade fotossintética. Outra diferença é que são mais duras/resistentes para evitar danos físicos (Rozendaal et al. 2006). Todavia, essas características demandam que a planta absorva água e 
recursos suficientes para produzir folhas com essas características. Portanto, as condições abióticas de alta radiação solar e geralmente baixa fertilidade do solo, encontradas em áreas em restauração, podem exercer uma pressão conflitante sobre a produção das folhas e em função disso a relação entre as características funcionais e as taxas de crescimento relativo das plantas não é observada.

A relação entre características funcionais foliares e a taxa de crescimento relativo pode ser influenciada pela ontogenia. Em estudos realizados em ambientes florestais, foi observado uma relação negativa entre massa foliar por área (MFA) e TCR em plântulas, mas em indivíduos maiores essa relação foi fraca ou inexistente (Poorter et al. 2008, Wright et al. 2010, Hérault et al. 2011). Ainda em ambientes florestais, Iida et al. (2014) encontraram relação negativa entre área foliar e TCR em indivíduos menores e relação positiva em indivíduos maiores. Além disso, nesse mesmo estudo, encontraram relação positiva entre MFA e TCR em indivíduos menores e relação negativa em indivíduos adultos. Essas mudanças na relação entre características funcionais e TCR também podem ser observadas em outros ambientes. Em uma área que está sendo restaurada e que foi utilizada como pasto no passado, Martinéz-Garza et al. (2013) não encontraram relação significativa entre o conteúdo de matéria seca foliar (CMSF) e crescimento em altura e diâmetro em indivíduos menores. Somente após 12-18 meses do plantio, quando os indivíduos estavam maiores, a relação foi significativa. Esses resultados sugerem que as características funcionais podem ter maior importância para a TCR em diferentes períodos ao longo do desenvolvimento das plantas.

No presente estudo, não foi encontrada relação entre a TCR medida em um intervalo de aproximadamente 36 meses e as características funcionais foliares atuais, medidas em indivíduos de tamanhos intermediários (médias das alturas das espécies variando entre 0,9 m e 6,4 m). Uma possível explicação para isso ter ocorrido é que no presente estudo as plantas 
ficaram expostas a uma alta densidade de gramíneas exóticas invasoras que chegaram a alcançar até 2 metros de altura durante um período de, no mínimo, 12 meses. Provendier \& Balandier (2008) verificaram que a competição entre espécies arbóreas e gramíneas resulta em uma diminuição da massa foliar por área (MFA), possivelmente porque a diminuição da radiação solar que faz com que as plantas tenham que construir folhas maiores para potencializar a captação de luz. Pillay \& Ward (2014) verificaram o mesmo resultado, mas com competição entre espécies arbóreas. Por outro lado, em ambientes com alta radiação solar, as espécies constroem folhas com valores de MFA maiores (Poorter et al. 2009-Causes and conse). Por outro lado, em ambientes com alta radiação solar, as espécies constroem folhas com valores de MFA maiores (Poorter et al. 2009-Causes and conse). No presente estudo, as espécies ficaram aproximadamente 18 meses interagindo com alta densidade de gramíneas exóticas invasoras. Essa interação pode ter afetado as espécies de forma diferente em relação às suas características funcionais, de modo que essas diferenças possam ter causado um ruído nas interações entre as características funcionais e a taxa de crescimento das espécies.

Apesar de não ter encontrado relação entre as características funcionais e a TCR, o modelo mais plausível na seleção de modelos indica que indivíduos maiores no início do monitoramento possuem menores TCR em altura. Diversas espécies apresentam taxas de crescimento dependente do tamanho (Hérault et al. 2011, Mencuccini et al. 2005, Rose et al. 2009, Iida et al. 2014) e isso pode ser causado por diferentes mecanismos. Por exemplo, depois de alcançar certo tamanho, muitas espécies param de investir recursos em crescimento em altura e passam a investir de outras formas. Geralmente o investimento em altura tem o objetivo de alcançar a copa e conseguir acesso à luz solar para a realização da fotossíntese. Quando as espécies alcançam a altura da copa, uma possibilidade para aumentar a captação de luz solar e consequentemente a fotossíntese é investir em expansão de cobertura de copa 
(crescimento lateral da copa) (Poorter, Bongers \& Bongers 2006) e não mais em crescimento em altura. Além disso, o transporte de água das raízes para as folhas das plantas ocorre primariamente devido à diferença de pressão entre esses dois órgãos. Quando a diferença de pressão é baixa, os canais por onde a água é transportada pode fechar e, assim, prejudicar o transporte. Para evitar que isso ocorra, as plantas fecham os estômatos para evitar que a pressão baixe, mas ao fechar os estômatos as plantas reduzem as trocam gasosas e a fotossíntese. Portanto, o custo de garantir o transporte de água em plantas maiores vem acompanhado com a redução das TCR (Koch et al. 2004). Em ambientes com alta radiação solar as plantas tendem a perder mais água por transpiração, portanto, é mais provável que esse processo fisiológico ocorra e que as plantas tenham as TCR reduzidas, principalmente as maiores. Neste estudo, indivíduos que já eram maiores no início apresentaram TCR menores.

\section{CONCLUSÕES}

No presente estudo não foi encontrada relação entre as características funcionais morfológicas e as taxas de crescimento relativo das plantas em uma área degradada que está sendo restaurada. Isso pode ser um indicativo de que essa abordagem não pode ser utilizada em todos os ambientes. No entanto, possivelmente existem outras características funcionais que podem estar relacionadas com as taxas de crescimento relativo, por exemplo, medidas fotossintéticas e conteúdo de nitrogênio foliar (Wrigth \& Westoby_2001, Poorter \& Bongers 2006). Estudos que avaliem características funcionais foliares em ambientes degradados e em diferentes estágios de desenvolvimento das plantas podem ajudar a avaliar se a seleção de espécies para projetos de restauração pode ser feita usando a abordagem de características funcionais. 


\section{REFERÊNCIAS BIBLIOGRÁFICAS}

Bates, D., M. Maechler, and B. Bolker. 2014. lme4:Linear mixed-effects models using Eigen and S4 classes. pp90. Disponível em: http://cran.rproject.org/web/packages/lme4/lme4.pdf. Acesso em: 15/06/2016.

Bartoń, K. 2015. MuMIn: multi-model inference. R package version 1.13.4. Disponível em: https://cran.r-project.org/web/packages/MuMIn/index.html. Acesso em: 15/06/2016

Bazzaz, F. A. 1979. The physiological ecology of plant succession. Annual Review of Ecology and Systematics 10:351-371.

Bechara, F.C., 2006. Unidades demonstrativas de restauração ecológica através de técnicas nucleadoras: Floresta Estacional Semidecidual, Cerrado e Restinga. Tese de Doutorado, Escola Superior de Agricultura Luiz de Queiroz, Universidade de São Paulo.

Bazzaz, F. A. and S. T. A. Pickett. 1980. The physiological ecology of tropical succession: a comparative review. Annual Review of Ecology and Systematics 11:287-310.

Bradshaw, A. D. 1983. The reconstruction of ecosystems. Journal of Applied Ecology 20:117.

Burnham, K. P. and D. R. Anderson. 2002. Model selection and multimodel inference - a practical information-theoretic approach, 2nd ed. Springer Science + Business Media, New York 488.

Chazdon, R. L. 2008. Chance and determinism in tropical forest succession. In W. P. Carson, and S. A. Schnitzer (Eds.). Tropical forest community ecology, pp. 384-408. Blackwell Publishing, Chichester, U.K.

Colangelo, A. C. 2012. Os parâmetros de resistência ao cisalhamento e a estabilidade das encostas no Planalto de Paraibuna e Serra de Caraguatatuba. Revista do Departamento de Geografia-USP volume especial 30 anos: 112-129.

Cornelissen, J., P.C. Diez, and R. Hunt. 1996. Seedling growth, allocation and leaf attributes in a wide range of woody plant species and types. Journal of Ecology 84:755-765.

Denslow, S. S. 1980. Gap partitioning among tropical rainforest trees. Biotropica 12:47-55.

Díaz, S., J. G Hodgson, K. Thompson, M. Cabido, J. H. C. Cornelissen et al. 2004. The plant traits that drive ecosystems: evidence from three continents. Journal of Vegetation Science 15:295-304.

Goldsmith, G. R., L. S. Comita, and S. C. Chua. 2011. Evidence for arrested succession within a tropical forest fragment in Singapore. Journal of Tropical Ecocology 27:323326. 
Guariguata, M., R. Rheingans, and F. Montagnini. 1995. Early woody invasion under tree plantation in Costa Rica: Implications for forest restoration. Restoration Ecolology 3: $252-260$.

Hatshorn, G. S. 1980. Neotropical forest dynamics. Biotropica 12:23-30.

Hoffmann, W. A., and H. Poorter. 2002. Avoiding bias in calculations of relative growth rate. Annals of Botany 90: 37-42.

Hodgson, J. G., G. Montserrat-Martí, M. Charles, G. Jones, P. Wilson, B. Shipley, M. Sharafi, et al. 2011. Is leaf dry matter content a better predictor of soil fertility than specific leaf area? Annals of Botany 108:1337-1345

Holl, K. D., M. E. Loik, E. H. V. Lin, and I. A. Samuels. 2000. Tropical montane forest restoration in Costa Rica: Over-coming barriers to dispersal and establishment. Restoration Ecology 8:339-349.

Iida, Y., T. S. Kohyama, N. G. Swenson, S. H. Su, C. T. Chen, J. M. Chiang and I-F. Sun. 2014. Linking functional traits and demographic rates in a subtropical tree community: the importance of size dependency. Journal of Ecology 102:641-650.

Johnson, J. B. and , K. S. Omland. 2004. Model selection in ecology and evolution. Trends in Ecology \& Evolution 19:101-108.

Koch, G. W., S. C. Sillett, G. M. Jennings, and S. D. Davis. 2004. The limits to tree height, Nature 428:851-854.

Koppen, W. 1948. Climatología. Fondo de Cultura Ecoómica, México.

Lusk, C. H., M. M. Pèrez-Millaqueo, F. I. Piper and A. Saldaña. 2011. Ontogeny, understorey light interception and simulated carbon gain of juvenile rainforest evergreens differing in shade tolerance. Annals of Botany 108: 419-428.

Lusk, C. H., M. A. Jorgensen and P. J. Bellingham. 2015. A conifer-angiosperm divergence in the growth vs. shade tolerance trade-off underlies the dynamics of a New Zealand warm-temperate rain forest. Journal of Ecology 103:479- 488.

Meziane, D. and B. Shipley. 2001. Direct and indirect relationships between specific leaf area, leaf nitrogen and leaf gas exchange. Effects of irradiance and nutrient supply. Annals of Botany 88: 915-927.

Martínez-Garza, C., V. Peña, M. Ricker, A. Campos, H.F. Howe. 2005. Restoring tropical biodiversity: leaf-traits predict growth and survival of late-successional trees in earlysuccessional environments. Forest Ecology and Management 217:365-379. 
Martínez-Garza, C., F. Bongers, and L. Poorter. 2013. Are functional traits good predictors of species performance in restoration plantings in tropical abandoned pastures? Forest Ecology and Management 303:35-45.

Martinez-Ramos, M. 1985. Claros ciclos vitales de lós arbores tropicales y regeneración natural de las Selvas Altas perennifolias. In: Gomez-Pompa, A. \& Del AMO. S. (eds) Investigaciones sobre La regeneracion natural de las selvas em Veracruz, Mexico. Ed. Alhambra Mexicana. Mexico, 191-240.

Mencuccini M, Martinez-Vilalta J, Vanderklein D, Hamid HA, Korakaki E, et al. 2005. Sizemediated ageing reduces vigour in trees. Ecology Letters 8:1183-90.

Meziane, D., and B. Shipley. 2001. Direct and indirect relationships between specific leaf area, leaf nitrogen and leaf gas exchange. Effects of irradiance and nutrient supply. Annals of Botany 88:915-927.

Mora, F., M. Martínez-Ramos, G. Ibarra-Manríquez, A. Pérez-Jímenez, J. Trill-eras, and P. Balvanera. 2014. Testing chronosequences through dynamicapproaches: time and site effects on tropical dry forest succession. Biotropica 47:38-48.

Nepstad, D., C. Uhl, and A. E. Serrao. 1990. Surmounting barriers to forest regeneration in abandoned highly degraded pastures: a case study from Paragominas, Para, Brasil. Pp 15-229. In A. B. Anderson, (ed). Alternatives to deforestation steps toward sustainable use of the Amazonas. Columbia University Press, New York.

Niinemets U. 1999. Components of leaf dry mass per area - thickness and density - alter leaf photosynthetic capacity in reverse directions in woody plants. New Phytologist 144: $35-47$.

Norden, N., H. A. Angarita, F. Bongers, M. Martínez-Ramos, I. Granzow-de la Cerda, M. van Breugel, et al. 2015. Successional dynamics in Neotropical forests are as uncertain as they are predictable. Proceedings of the National Academy of Sciences of the United States of America 112:8013-8018.

Paine, C. E. T., M. Stenflo, C. P. Philipson, P. G. Saner, R. R. Bagchi, R. C. Ong, et al. 2012. Differential growth responses in seedlings of ten species of Dipterocarpaceae to experimental shading and defoliation. Journal of Tropical Ecology 28:377-384.

Pérez-Harguindeguy, N., S. Díaz, E. Garnier, et al. 2013. New handbook for standardised measurement of plant functional traits worldwide. Australian Journal of Botany 61:167234. 
Pillay, T. and D. Ward. 2014. Competitive effect and response of savanna tree seedlings: comparison of survival, growth and associated functional traits. Journal of Vegetation Science 25: 226-234.

Pinheiro, J. and D. Bates. 2000. Mixed-effects models in S and S-PLUS. Springer, New York. pp 3-52.

Pinã-Rodrigues, F. C. M., L. G. S. Costa and A. Reis. 1990. Estratégias de estabelecimento de espécies arbóreas e o manejo de florestas tropicais. In: Anais do $6^{\circ}$ Congresso Florestal Brasileiro. Campos de Jordão, pp. 677-684.

Poorter L. 1999. Growth response of 15 rain-forest tree species to a light gradient: the relative importance of morphological and physiological traits. Functional Ecology 13: 396-410.

Poorter, L., and F. Bongers. 2006. Leaf traits are good predictors of plant performance across 53 rain forest species. Ecology 87:1733-1743.

Poorter, L., L. Bongers, and F. Bongers. 2006. Architecture of 54 moist forest tree species: traits, trade-offs, and functional groups. Ecology 87:1289-1301

Poorter, L. 1999. Growth responses of 15 rain-forest tree species to a light gradient: the relative importance of morphological and physiological traits. Functional Ecology $13: 396-410$.

Poorter H, and E. Garnier. 1999. Ecological significance of inherent variation in relative growth rate. In: Pugnaire F, Valladares X, (eds). Handbook of functional plant ecology. New York, USA: Marcel Dekker, 81-120.

Poorter, L., H. Paz, S. J. Wright, D. D. Ackerly, R. Condit, G. Ibarra-Manríquez, et al. 2008. Are functional traits good predictors of demographic rates? Evidence from five neotropical forests. Ecology 89:1908-1920.

Poorter, H., U. Niinemets, L. Poorter, I. J. Wright, and R. Villar. 2009. Causes and consequences of variation in leaf mass per area (LMA): a meta-analysis. New Phytologist 182:565-588.

Provendier, D. and P. Balandier. 2008. Compared effects of competition by grasses (Graminoids) and broom (Cytisus scoparius) on growth and functional traits of beech saplings (Fagus sylvatica). Annals of Forest Science ,65, article 510.

Pywell, R. F., J. M. Bullock, D. B. Roy, L. Warman, K. J. Walker, and P. Rothery, 2003. Plant traits as predictors of performance in ecological restoration. Journal of Applied Ecology 40:65-77. 
R Development Core Team. 2015. A language and environmet for statistical computing. $\mathrm{R}$ Foudation for Statistical Computing, Vienna, Austria. ISBN 3-900051-07-0, URL http://www.R-project.org/.

Rasband, W. S. 2007. ImageJ. Versão: 1.42q. National Institute of Health, USA.

Reich, P. B., M. B. Walters, and D. S. Ellsworth. 1997. From tropics to tundra: global convergence in plant functioning. Proceedings of the National Academy of Sciences (USA) 94:13730-13734.

Reich, P. B., D. S. Ellsworth, M. B. Walters, J. Vose, C. Gresham, J. Volin, and W. Bowman. 1999. Generality of leaf traits relationships: a test across six biomes. Ecology 80:19551969.

Reich, P. B., I. Wright, J. Cavender-Bares, J. Craine, J. Oleksyn, M. Westoby, and M. B. Walters. 2003. The evolution of plant functional variation: traits, spectra, and strategies. International Journal of Plant Sciences 164:143-164.

Reich, P. B. 2014. The wolrd "fast-slow" plant economics spectrum: a traits manifesto. Journal of Ecology 102:275-301.

Rose, K. E., R. L. Atkinson, L. A. Turnbull, and M. Rees. 2009. The costs and benefits of fast living. Ecology Letters 12:1379-1384.

Rozendaal, D. M. A., V. H. Hurtado and L. Poorter. 2006. Plasticity in leaf traits of 38 tropical trees species in response to light; relationships with light demand and adult stature. Functional Ecology 20:207-216.

Ruger N, C. Wirth , S. J. Wright , R. Condit. 2012. Functional traits explain light and size response of growth rates in tropical tree species. Ecology 93:2626-2636.

Ruiz-Jaen, M. C. and T. M. Aide. 2005. Restoration success: how is it being measured? Restoration Ecology 13:569-577.

Sarmiento, F. O. 1997. Arrested succession in pastures hinders regeneration of Tropandean forests and shreds mountain landscapes. Environmental Conservation 24:14-23.

SER 2004. The SER Primer on Ecological Restoration, Version 2. Society for Ecological Restoration Science and Policy Working Group, http://www.ns.ser.org/content/ecological_restoration_primer.asp acesso em: $12 / 08 / 2015$.

Sterck, F. J., L. Poorter, and F. Schieving. 2006. Leaf traits determine the growth-survival trade-off across rain forest tree species. American Naturalist 167: 758-765.

Swaine, M.D. and T. C. Whitmore. 1988. On the definition of ecological species groups in tropical rain forests. Vegetagio 75: 81-86. 
Thomas, S.C. 1996. Relative size at onset of maturity in rain forest trees: a comparative analysis of 37 Malaysian species. Oikos 76:145-154.

Turner, I. M. 1994. A quantitative analysis of leaf form in woody plants from the world's major broadleaved forest types. Journal of Biogeography 21:413-419.

Uhl, C., R. Buschbacher, and E. A. S. Serrão. 1988. Abandoned pastures in eastern Amazonia I. Patterns of plant succession. Jounal of Ecology 76:663-681.

Vasquez-Yanes, C. and S. Guevara-Sada, 1985. Caracterizacion de os grupos ecologicos de arboles de la selva humeda. Regeneracion de Selvas II, Compania Editorial Continental, Mexico, pp 67-78.

Violle, C., M. L. Navas, D. Vile, E. Kazakou, C. Fortunel, I. Hummel, and E. Garnier. 2007. Let the concept of trait be functional! Oikos 116:882-892.

Violle, C., E. Garnier, J. Lecoeur, C. Roumet, C. Podeur, A. Blanchard and M. L. Navas. 2009. Competition, traits and resource depletion in plant communities. Oecologia 160:747-755.

Whitmore, T. C. 1982. On pattern and processe in forests. In: Newman, E.I. (ed) The plant community as a working mechanism. British Ecological Society, Special publication. $\mathrm{N}^{\circ}$ 1', Blackwell Scientific publication, Oxford.

Wright, I., P. B. Reich, and M. Westoby, and GLOPNET researchers. 2004. The worldwide leaf economics spectrum. Nature 428:821-827.

Wright, S. J., K. Kitajima, N. J. B. Kraft, P. Reich, I. J. Wright, D. E. Bunker, R. Condit, et al. 2010. Functional traits and the growth mortality trade-off in tropical trees. Ecology 91:3664-3674.

Zahawi, R. A. and C. K. Augspurger. 1999. Early plant succession in abandoned pastures in Ecuador. Biotropica 31:540-552. 


\section{ANEXOS}

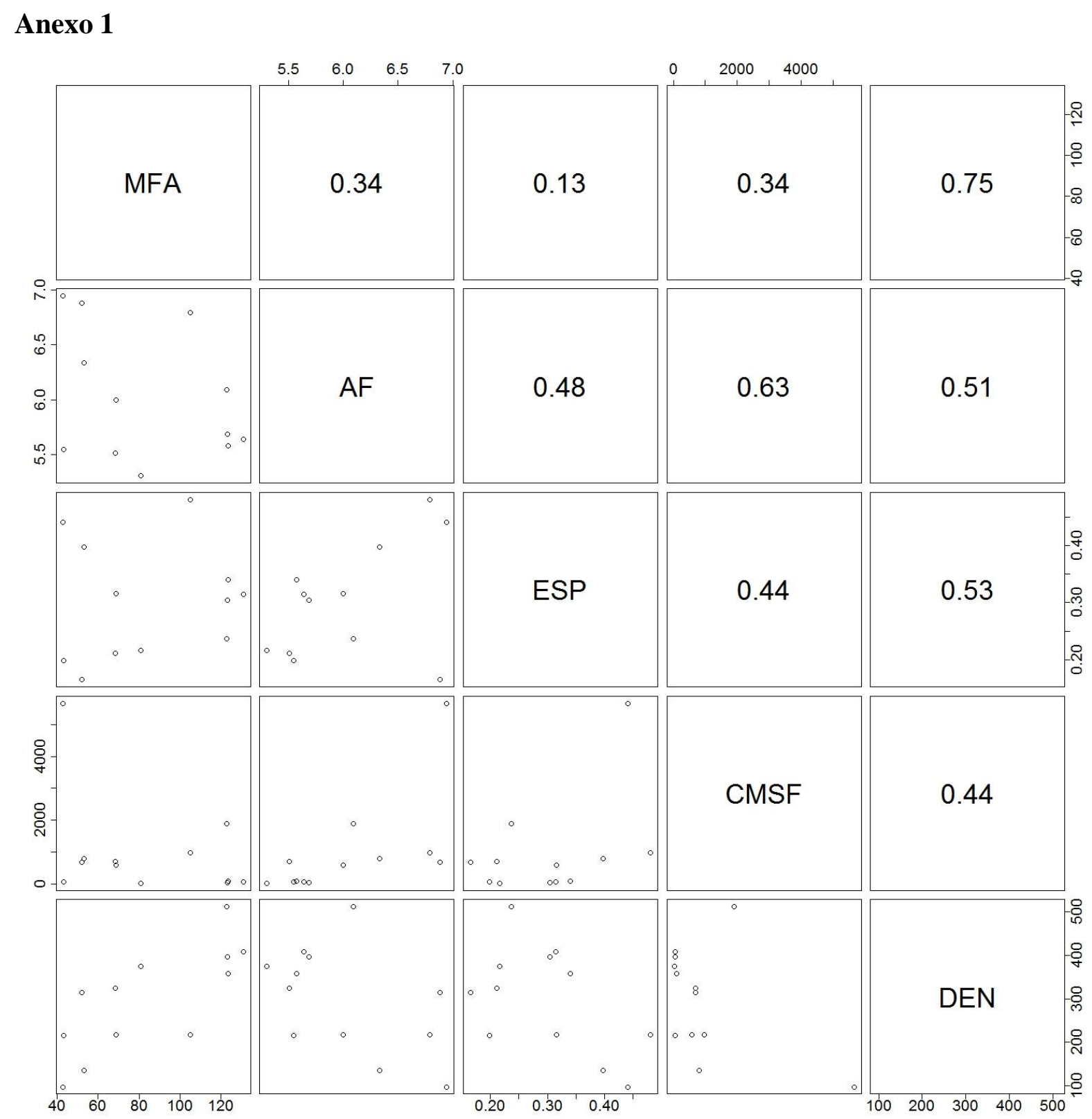

Figura S1: Gráficos de correlação (inferior) e valores de correlação de Pearson (superior) entre as características funcionais. MFA: massa foliar por área, AF: área foliar, ESP: espessura foliar, CMSF: conteúdo de matéria seca da folha e DEN: densidade da folha. 